\title{
Justiça Penal e Justiça de Familia: a Guarda Compartilhada e a Proteção Que Desprotege
}

\begin{abstract}
SORAIA DA ROSA MENDES
Doutora em Direito, Estado e Constituição pela UnB, Mestre em Ciência Política pela UFRGS, Professora do PPG - Mestrado em Direito do Instituto de Direito Público do IDP, Líder do Grupo Sistema Penal e Garantias Fundamentais - CNPq/DP. E-mail: professorasoraiadarosamendes@gmail.com.
\end{abstract}

Data de Submissão: 05.10.2016

Data da Decisão Editorial: 21.10.1991

Data da Comunicação ao Autor: 21.10.2016

RESUMO: Este artigo tem como principal objetivo apresentar dados e levantar questionamentos quanto à práxis judiciária que recepciona as demandas decorrentes da violência doméstica e familiar contra a mulher em seu aspecto criminal e às atinentes ao término da relação conjugal em compartimentos estanques. A tese que se propõe é a de que a insensibilidade de gênero de parte do Poder Judiciário é um fato gerador de desproteção, na medida em que, em regra, em casos a envolver violência doméstica, a resolução de disputas relacionadas aos(às) filhos(as) reflete mais uma face de um conflito que não se esgota (ou que, pior, pode ser acirrado) com uma decisão judicial a determinar a guarda compartilhada.

PALAVRAS-CHAVE: Violência doméstica; direito fundamental de proteção; guarda compartilhada; justiça.

ABSTRACT: This article aims to present data and raise questions about judicial praxis that welcomes the demands arising from domestic and family violence against women in its criminal aspect, and those relating to the termination of the marital relationship in watertight compartments. The thesis proposes is that the insensitivity of gender from Judiciary is a fact generator of unprotection, to the extent that, as a rule in cases involving domestic violence, the resolution of disputes related for children as reflects more a face of a conflict that does not end (or worse, can be fierce) with a court decision to determine the joint custody.

KEYWORDS: Domestic violence; right to protection; joint custody; justice.

SUMÁRIO: Introdução; 10 direito fundamental à proteção: da Constituição à Lei Maria da Penha; 2 Guarda compartilhada e proteção integral: a quem se protege?; Considerações finais; Referências. 


\section{INTRODUÇÃO}

"Sede submissos uns aos outros no temor de Cristo, as mulheres aos homens como ao Senhor" (Efésios, 5:21).

Embora a frase destacada em epígrafe tenha origem milenar, representa uma excelente chave de compreensão de como, no final da Idade Média, passa a ser (re)firmada ideia de que um bom casamento seria a comunhão entre um homem e uma mulher, na medida em que o homem governasse e a mulher a ele obedecesse incondicionalmente. A união entre um homem e uma mulher marcava-se, portanto, pelo poder masculino e pela submissão feminina, garantidos, entre outras, também pelas estruturas judiciais disponíveis à época.

A posição de poder absoluto do marido, referendada por autoridades eclesiásticas e laicas, constitui, nessa época, o ideal da sociedade masculina. E, como retrata a história, os casos criminais do final da Idade Média provam a dureza que esta estrutura de poder patriarcal impunha sobre as mulheres.

Dentro de um contexto de violência "legítima", ser uma mulher de família era ser também mãe, e ser mãe era exercer uma função pedagógica (embora condicionada) em relação aos filhos.

É bem verdade que a noção de família mudou muito desde os tempos remotos mencionados, podendo significar, hoje, a coexistência sob o mesmo teto de pai/mãe, avó/avô, tios/tias, primos/primas e/ou irmãos/irmãs; ou mesmo formas de viver em conjunto que envolvem pessoas unidas não por laços de parentesco civil, mas por enlaces de amizade ou, até mesmo, interesse econômico.

Contudo, mesmo sendo outra(s) a(s) família(s), as relações que se estabelecem em seu interior permanecem profundamente marcadas pelo mito da responsabilidade materna quanto à educação e os cuidados com os(as) filhos(as) e pela subordinação das mulheres, não raro pela violência. Isto é, seja qual for o modelo familiar, este ainda é um locus de poder e dominação masculino, um espaço de poder selvagem (Ferrajoli, 2006), no qual impera a lei do mais forte mediante a violência, seja ela física, sexual, psicológica, moral e/ou patrimonial.

De outra banda, assim como servia o Tribunal do Ofício parisiense como uma instância legitimadora do poder masculino e da submissão feminina, a práxis judiciária atual, na medida em que aloca "questões criminais" 
e "questões de família" em diferentes compartimentos (quase incomunicáveis, como veremos) quando o fio conduto são demandas decorrentes da violência doméstica e familiar contra a mulher, acaba, no mais das vezes, ainda que tacitamente, por acirrar conflitos e aumentar os riscos de que novos atos de violência contra a mulher sejam perpetrados.

Afinal, até que ponto, sob o argumento do melhor interesse das crianças e/ou adolescentes, a determinação de que haja a guarda compartilhada entre pai e mãe, em casos marcados pela violência doméstica contra a muIher, pode ser considerada protetiva?

A hipótese que traço é a de que a guarda compartilhada em contextos como este, marcados por formas de violência conhecidas pelas mulheres ao longo da história, no mais das vezes, não protege nem a criança e/ou adolescente nem a mulher vítima de violência doméstica, caracterizando, sim, decisões que acabam por constituírem-se como mais um fato gerador de desproteção.

\section{DIREITO FUNDAMENTAL À PROTEÇÃO: DA CONSTITUIÇÃO À LEI MARIA DA PENHA}

Como ensina Ferrajoli (2005), responder à pergunta "o que são direitos fundamentais?" envolve uma abordagem que pode se dar sob quatro diferentes ângulos: o da justiça, o da validade, o da efetividade e o da teoria do Direito. Interessa-me, neste momento, mais especificamente, o terceiro aspecto, ou seja: o ponto de vista da efetividade, ângulo sob o qual os direitos fundamentais são assim tomados não em razão da normatividade, mas por aquilo que de fato acontece ou aconteceu no ordenamento em relação à concreta tutela ou concreta violação dos direitos neste estabelecidos.

A construção histórica dos direitos fundamentais não é, portanto, meramente teórica. Pelo contrário, os direitos fundamentais são o resultado de disputas políticas, sociais, econômicas, etc. E foi nesse campo de disputa que o feminismo, enquanto movimento social e político, vem construindo, a partir da denúncia da violência a que historicamente as mulheres são submetidas, o direito à proteção contra a violência.

$\mathrm{Na}$ história recente brasileira, mais especificamente na década de 1980, o período de instauração e funcionamento da Assembleia Nacional Constituinte representou um significativo momento quanto ao tipo de participação das mulheres no processo político e o consequente resultado desta em termos de constitucionalização de seus direitos. 
Apesar do fato de a bancada feminina na ANC ser composta por apenas $5,7 \%$ de deputadas federais constituintes (e nenhuma senadora), sendo estas parlamentares, em sua maioria esmagadora, desvinculadas de uma pauta mais específica para as mulheres ${ }^{1}$, as organizações feministas foram capazes de exercer suficiente pressão tanto sobre essas mesmas deputadas ${ }^{2}$ quanto sobre o conjunto do Parlamento e, com isso, transformar em direitos e garantias constitucionais aquelas que eram (e muitas ainda são) suas principais reivindicações.

Essa indelével característica do grupo de parlamentares, autodenominada "bancada feminina", mutatis mutandis, não impediu, assim, que 30 emendas sobre os direitos das mulheres fossem apresentadas. Uma atuação marcante que decorreu, principalmente, de três fatores fundamentais.

O primeiro, a existência de três emendas populares, a demonstrar a capacidade mobilizadora do movimento na esfera pública e o flagrante anseio coletivo de que fossem positivados direitos e garantias que dissessem com a igualdade entre trabalhadores e trabalhadoras, o direito igualitário de posse da terra, a legalização do aborto e as políticas eliminação da violência.

O segundo, a forte presença do Conselho Nacional dos Direitos da Mulher - CNDM (criado em agosto de 1985) como um catalisador de esforços constantes de atuação junto aos constituintes e, em particular, às constituintes. E o terceiro pela "própria dinâmica interna da Câmara dos Deputados, espaço privilegiadamente masculino que, certamente, colaborou para o crescimento de uma identidade e de uma solidariedade feminina" entre as 26 deputadas (Pinto, 2003, p. 74).

Foi por iniciativa do CNDM que, ainda antes do início dos trabalhos da $A N C$, realizou-se uma reunião com um grande número de feministas na qual foi elaborada a denominada Carta das Mulheres, um instrumento que trazia em seu conjunto as principais demandas, à época, das brasileiras.

1 Como aponta Céli Pinto (2003), o recrutamento das eleitas em regra atendeu a moldes clássicos que incluíam o fato de pertencerem a famílias de políticos ou de terem angariado popularidade por sua atuação nos meios de comunicação ou profissional. De fato, pouquíssimas das 26 constituintes tinham uma trajetória a partir dos movimentos de mulheres dentro ou fora dos partidos políticos (Pinto, 2003, p. 73).

2 É interessante notar que um grupo expressivo de candidatas que disputavam o pleito para a legislatura de 1986 a 1990 alegavam nunca terem pensado em disputar um mandato eletivo, mas que teriam cedido à pressão e à insistência do partido, que nelas via figuras de prestígio junto a comunidades ou categorias profissionais. Pela análise das entrevistas realizadas por Tabak (2002), muitas das candidatas não tinham nenhuma familiaridade com a estrutura partidária, com o programa e os estatutos, com a prática da militância e, inclusive, com a natureza de uma Assembléia [sic] Nacional Constituinte. 
O lema era "Constituinte pra valer tem que ter direitos da mulher!" (Pitanguy, 2008). E, sob esta consigna, a Carta das Mulheres foi entregue ao Deputado Ulisses Guimarães, então Presidente do Congresso Nacional, em março de 1987, quando da inauguração da Assembleia Nacional Constituinte, com o objetivo simbólico de evidenciar o caráter nacional e articulado da atuação das mulheres naquele espaço de (re)inauguração do Estado brasileiro.

Para além do preâmbulo e dos princípios gerais, a Carta das Mulheres trouxe, na segunda parte do texto, reivindicações específicas quanto à família, ao trabalho, à saúde, à educação e cultura e à violência (Mendes, 2013). E, no que toca à violência doméstica, a demanda era pela criminalização de quaisquer atos que envolvessem agressões físicas, psicológicas ou sexuais à mulher fora e dentro do lar. De modo que o art. 228, § $8^{\circ}$, da Constituição Federal de 1988 e todas as normativas infraconstitucionais daí decorrentes, entre estas a Lei Maria da Penha, são a comprovação deste fato em nossa história recente.

Os direitos fundamentais, por outro lado, exigem, como condições de efetividade, a introdução das respectivas garantias mediante leis de atuação. Como explica Ferrajoli (2005, p. 102):

A existência de uma norma constitucional sobre o direito à saúde, por exemplo, não implica a existência das relativas garantias se essas não tiverem sido introduzidas, na atuação de tal direito, com a instituição de serviços de saúde gratuitos para todos. Nem mesmo o homicídio seria punível por força da simples existência do direito à vida se não fossem as leis penais e processuais que o preveem como delito e disciplinam a investigação e a punição.

Sabemos que é possível que inexistam - mesmo que devessem existir - obrigações ou vedações correspondentes a um direito fundamental por causa da (indevida) inexistência da norma que os preveja. Esse era o caso, entre nós, do § 80 do art. 226 da Constituição Federal de 1988, cuja concreção efetiva somente se dá em 2006, com a promulgação da Lei no 11.340 , conhecida como Lei Maria da Penha.

Todos os direitos fundamentais são (e se justificam enquanto tais), como ensina Ferrajoli (2006), leis dos mais fracos que se põem em alternativa às leis dos mais fortes que vigoram na sua ausência. E, nesta ordem de ideias, em primeiro lugar, está o direito à vida, contra a lei de quem é mais forte fisicamente; em segundo lugar, os direitos de imunidade e de liberdade, contra a lei de quem é mais forte politicamente; em terceiro lugar, os 
direitos sociais, que são os direitos à sobrevivência, contra a lei de quem é mais forte social e economicamente.

Exatamente porque os direitos fundamentais são sempre leis dos mais fracos contra a lei dos mais fortes que têm validade como direitos do indivíduo para proteger as pessoas também - e acima de tudo - contra as suas culturas e, até mesmo, contra suas famílias: a mulher contra o pai e o marido, o menor contra os pais e, em geral, os oprimidos contra suas culturas opressivas (Ferrajoli, 2011, p. 107).

É neste sentido que o direito à proteção se coloca como um vetor estruturante a partir do qual devem ser deduzidos os limites e a necessidade de atuação do direito penal e de família nas situações que envolvem a violência de gênero, ou, mais especificamente, a violência doméstica e familiar contra a mulher.

Vale citar que o Comitê responsável pelo monitoramento da Convenção para a Eliminação de Todas as Formas de Discriminação contra a Mulher, na Recomendação Geral no 19, sobre violência contra a mulher, a discriminação incluiu a violência de gênero entendida como a violência dirigida especificamente contra a mulher por ser mulher ou que a afeta de maneira desproporcional. Essa violência inclui atos que causem ou possam causar dano ou sofrimento físico, sexual ou psicológico às mulheres, incluindo ameaças, coerção e outras formas de restrição de liberdade.

A prática, ou o uso, da violência contra a mulher constitui um elemento fundamental para entender as desigualdades que caracterizam homens e mulheres em nossa sociedade (Bandeira e Thurler, 2009, p. 162). No caso da violência doméstica, o objetivo fundamental não é nem tanto, prioritariamente, o de ferir, mas o de marcar poder e autoridade. Como ensinam Bandeira e Thurler (2009, p. 163):

Fica evidente que o objetivo de tal conduta é a de introduzir o controle, o medo e, até mesmo, o terror na companheira, caso ela não siga as regras de conduta e dos mandatos que lhe são impostos pelo marido/companheiro. Em tais situações o fiel da balança centra-se nas ameaças constantes para manter o equilíbrio da situação de controle na conjugalidade. As consequências são imediatas e visíveis, com sofrimentos físicos e psíquicos [...].

Prosseguem Bandeira e Thurler (2009, p. 164) dizendo que:

A especificidade das práticas de violência contra a mulher é thes deixar bem explicitado quem é o detentor da autoridade no espaço doméstico-familiar e que a "sua" mulher deve estar submetida a tais normas, sabendo, inclusive, que a 
qualquer momento poderá prestar contas a seu marido/companheiro, caso ele assim o desejar.

Não raro, como veremos adiante, a disputa pelos(as) filhos(as) nas Varas de Família são um reflexo da multifacetada violência de que a mulher é vítima no âmbito doméstico. De modo que, dentro dos limites constitucionais, a resposta punitiva não é mais do que um elemento excepcional e possível em integração com outros instrumentos protetivos de outras searas do Direito (família, por exemplo), que exige de todo o sistema de justiça sensibilidade de gênero. Ou seja, que exigem que se compreenda o gênero enquanto elemento constitutivo que pressupõe a construção social dos indivíduos relacionado à ideia de mulher e de homem. Uma construção na qual é importante, senão vital, a difusão de símbolos culturalmente disponíveis que agregam representações múltiplas sobre o feminino e o masculino. Símbolos, dotados de uma ideia de permanência intertemporal, interpretados e introduzidos por meio de conceitos normativos, tais como os encontrados nas doutrinas religiosas, nas práticas educacionais e nas leis (Scott, 2003). Como forma primária de relações de poder, o gênero é um campo no qual, ou mediante o qual, se articula o poder; uma forma habitual de facilitar a significação do poder, que conceitualiza e constitui o próprio poder.

\section{GUARDA COMPARTILHADA E PROTEÇÃO INTEGRAL: A QUEM SE PROTEGE?}

Nos termos do $\S 8^{\circ}$ do art. 226 da Constituição Federal de 1988, compete ao Estado assegurar a assistência à família mediante mecanismos que coíbam a violência no âmbito de suas relações. A Lei no 11.340/2006, conhecida como Lei Maria da Penha, é a norma que reconhece a violência doméstica e familiar contra a mulher como impeditiva ao exercício efetivo, entre outros, dos direitos à vida, à segurança, ao acesso à justiça, à cidadania, à liberdade, à dignidade, ao respeito e à convivência familiar (grifei) e comunitária, prevendo, a partir deste reconhecimento, a criação de medidas de assistência e proteção às mulheres em situação de violência doméstica e familiar, assim como a instalação de Juizados de Violência Doméstica e Familiar contra a Mulher.

Em que pese a competência dos Juizados ou Varas de Violência Doméstica e Familiar contra a Mulher, conforme dados da Comissão Parlamentar Mista de Inquérito (Senado Federal, 2013), cuja finalidade foi a de investigar a situação da violência contra a mulher no Brasil e apurar denúncias de omissão por parte do poder público com relação à aplicação de instrumentos instituídos em lei para proteger as mulheres em situação de violência", 
em diferentes Estados brasileiros, as ações de natureza de família, mesmo quando decorrentes de violência doméstica, correm perante as Varas de Família sem que, de regra, no mínimo, haja um canal formal de comunicação entre os(as) magistrados(as) que deferem medidas protetivas de, por exemplo, proibição de aproximação e os(as) juízes(as) que determinam a guarda compartilhada dos(as) filhos(as).

Eis aí o ponto nevrálgico da problemática que gira em torno das searas de família e criminal. Isto é, para além da discussão sobre os reflexos da guarda compartilhada, está a incompreensão sistêmica de que a violência doméstica não se compartimentaliza neste ou naquela instância decisória. E mais: de que tal práxis, como apontada no relatório da CPMI, comum em vários Tribunais brasileiros, menospreza os diversos aspectos (moral, psicológico, patrimonial) que a violência contra a mulher assume em uma situação de conflito doméstico.

Em pesquisa ${ }^{3}$ finalizada sob minha coordenação, uma das entrevistas realizadas com um(a) magistrado(a) (cuja identificação será mantida em sigilo) responsável por uma das Varas de Violência Doméstica e Familiar contra a Mulher no Distrito Federal, ao ser perguntado(a) sobre a relação com a Vara de Família, assim respondeu ao pesquisador e à pesquisadora:

Pesquisador(a): Qual é a relação que há com a Vara de Família? Porque uma das questões que temos visto é que há uma desconexão complete, onde um Juiz da Vara de Família está completamente alijado daquilo que aconteceu na Vara de Violência Doméstica e Familiar. Então ele está tratando da separação e de uma série de outras coisas que são decorrentes da família, mas não sabe que tem todo um histórico de violência.

Magistrada(o): Por exemplo, na questão da guarda, se eles (os agressores) argumentam que foi dada medida protetiva para ela, mas não foi dada para os filhos e que ele deseja ver as crianças. Então faço uma audiência e pergunto para ela a quem da família posso entregar a criança. Se ela responde que ele nunca maltratou a criança e que é um bom pai, pergunto a ela a quem da família dela pode entregar a criança para ele em determinados dias. Se ela sugere uma tia, por exemplo, a ele pergunto se tem alguém que possa receber a criança.

Pesquisador(a): Mas como isso vem para os autos? Isso eles resolvem na Vara de Família?

3 Refiro-me à pesquisa "Solução de conflitos envolvendo violência doméstica e familiar contra a mulher: uma análise da práxis dos juizados do Distrito Federal", por mim coordenada junto ao PPG Mestrado em Direito do Instituto de Direito Público - IDP, em parceria com Ministério Público do Distrito Federal e Territórios - Projeto MP Eficaz - Lei Maria da Penha. 
Magistrada(o): Não. Eles (os agressores) vêm aqui, pela medida protetiva, quando elas pedem a medida protetiva na delegacia. Ou, então, elas pedem a medida protetiva e, durante o processo, geralmente um advogado particular informa que ela não está deixando ele ver as crianças. Então, eu marco uma audiência para conhecer a situação e, em alguns casos, em que ele é alcoólatra e não tem condições, eu aviso que ele não verá os filhos enquanto não apresentar uma resposta de que está bem e de que tenha condições. Quando há algum processo em Vara de Família e que eles me informam, aí eu comunico.

Pesquisador(a): Mas te informam, normalmente?

Magistrada(o): Informam. Elas falam em audiência que há um processo de guarda, e ele, pelo advogado, ou informam à Defensoria Pública.

Pesquisador(a): E quando já tem um processo aqui e depois ingressa com um processo de guarda, o Juiz de lá também informa que...

Magistrada(o): Não. Nunca informa.

Pesquisador(a): Ele pode deferir, lá, a guarda compartilhada, por exemplo, sem que você tenha conhecimento e tenha uma medida protetiva.

Magistrada(o): Pode.

Pesquisador(a): Já aconteceu?

Magistrada(o): Nunca fiquei sabendo.

Pesquisador(a): Mas pode acontecer?

Magistrada(o): Pode. Eu informo. Se eu sei que eles estão discutindo e que há um processo, eu oficio informando que há uma decisão, encaminho cópia da decisão.

Pesquisador(a): Dentro desse manual cartorário que é usado pelo CNJ seria interessante uniformizar esse fluxo processual, de uma forma interligada, a fim de que o Juiz da Vara de Família também soubesse o que o Juiz da Vara de Violência Doméstica está decidindo? Principalmente em função dessa imposição de guarda compartilhada.

Magistrada(o): Com certeza. É uma das coisas que estamos sentindo aqui, quando eles ameaçam que vão pedir a guarda compartilhada e elas vêm desesperadas, dizendo que eles vão pedir a guarda compartilhada. Informo que não é assim, dou a medida protetiva e aviso à Vara de Família de que existe uma decisão em um processo de violência doméstica.

Os trechos anteriormente transcritos são somente exemplificativos da rotina judiciária no Distrito Federal e que se repete (não é audacioso referir) em diversas partes do Brasil. 
Contudo, mais espantoso é, ainda, como já anunciado alhures, perceber o quanto a compreensão secular baseada em estereótipos de gênero no âmbito do Juízo de Família pode ir além.

Vejamos que, conforme dados levantados por Oliveira (2015), em nosso País, em 2012, foram concedidos 146.766 divórcios em primeira instância a casais com filhos(as) menores de idade. Desse total, em 127.849 (aproximadamente $87 \%$ ), as mulheres ficaram responsáveis pela guarda dos(as) filhos(as), sendo que aos homens foi atribuída a responsabilidade em 7.885 dos casos (6\% aproximadamente). Foram 8.737 casos de guarda compartilhada.

No Distrito Federal, foram proferidas 3.949 decisões concessivas de divórcio em 2012. Desse universo, somente em 216 casos os homens ficaram responsáveis pela guarda dos(as) filhos(as), sendo que às mulheres houve 3.316 decisões. A guarda compartilhada ocorreu em somente 326 decisões.

O que esses dados mostram é que, como conclui o pesquisador, na regulamentação dos pedidos de guarda, o Código Civil de 2002 reconheceu um direito das crianças, mas não promoveu redistribuição da tarefa de cuidados e demais encargos advindos da criação dos(as) filhos(as). As obrigações de cuidado e educação, ironicamente, tal como pensava-se na Idade Média, permanecem na alçada das mulheres.

De outra banda, é interessante notar que essa mesma ênfase aos(às) filhos(as), que é dada quando se trata da guarda, não se repete na estipulação dos regimes de bens e nas formas de divisão do patrimônio em comum quando ocorre o divórcio ou a dissolução da união estável. Nessa matéria, como afirma Oliveira (2015):

Prevalece a lógica da igualdade formal, que atribui $50 \%$ a cada um dos cônjuges dos bens adquiridos em comum. Não entram na conta os ônus decorrentes do divórcio, tais como, por exemplo, da guarda dos(as) filhos(as).

O reconhecimento dos direitos fundamentais é uma exigência da dignidade da pessoa humana, que impõe ao Estado um dever maior do que o de meramente abster-se de afetar, de modo desproporcional e desarrazoado, a esfera patrimonial das pessoas sob a sua autoridade. Sendo exigíveis, também, e portanto, ações positivas que podem concretizar-se tanto por meio de normas penais, de normas procedimentais, de atos administrativos ou até mesmo pela atuação concreta dos poderes públicos, no caso em discussão neste artigo, do Poder Judiciário. 
Considerado o dever de proteção estatal, é outorgado ao indivíduo o correspondente direito de exigir do Estado que este o proteja (Alexy, 2002), cabendo ao Estado zelar, inclusive preventivamente, pela proteção dos indivíduos, não somente contra ingerências indevidas de parte dos poderes públicos, mas também contra agressões provenientes de particulares. Essa esfera protetiva toma especial relevo quando se trata de definir o que se deve exigir do Estado para que proteja a mulher vítima em qualquer esfera do sistema de justiça que se encontre.

É fato que a guarda compartilhada, introduzida pela Lei nº 11.698/1998, que recebeu os contornos de sua significação judicial a partir da entrada em vigor da Lei nº 13.058/2014, ao passo que estabeleceu a obrigatoriedade dessa modalidade de guarda mesmo quando não houver acordo entre pai e mãe, também teve como elemento positivo o objetivo de propiciar o livre exercício dos direitos referentes à maternidade e à paternidade e de buscar evitar a alienação parental.

Contudo, nas disputas pela guarda dos(as) filhos(as), o "cuidado" com estes muitas vezes reacende pontos de tensão, na medida em que demanda o contato constante entre genitor e genitora nas situações cotidianas. $\mathrm{Ou}$ seja, essas contendas normalmente suscitam questões que devem ser analisadas para além dos cuidados com as crianças e/ou adolescentes, pois, quando a violência doméstica se mostra presente, o compartilhamento da guarda transcende o "desejo de cuidado", mas reflete sim o exercício de poder de que nos falavam anteriormente Bandeira e Thurler (2009).

Concordo integralmente com Oliveira (2015) quando, a partir de sua pesquisa, afirma sobre o princípio do melhor interesse do menor (criança ou adolescente) $)^{4}$ que:

A utilização deste princípio no discurso oficial, na concepção clássica acima enunciada, pode refletir o "mito da mulher mãe". Conforme Badinter (1985, p. 338), no cuidado com os(as) filhos(as), há uma dualidade de papéis atribuídos às mulheres, quais sejam, o materno (centralizado na casa) e o feminino (voltado para o espaço público). Embora se tenha uma crença acerca da complementariedade entre estes dois papéis, se houver antagonismo, "a única solução sugerida para pôr fim ao conflito dos dois papéis é eliminar um deles, ou seja, o trabalho feminino fora do lar".

40 princípio do melhor interesse do menor (criança ou adolescente) está previsto tanto na Convenção Internacional de Haia (1993) e no Pacto de São José da Costa Rica (1969) quanto no plano do direito interno, no art. 227 da Constituição de 1988, bem como no ECA e nos arts. 1.583 e 1.584 do Código Civil de 2002. 
Quer parecer ser invisível aos olhos de quem sustenta tão somente a proteção do interesse do menor em um processo de família que a violência não atinge somente a mulher, mas a todos(as) que com ela se relacionam, muito especialmente os(as) filhos(as).

É de ver-se, contudo, que, como apontam Diniz e Angelim (2003, p. 26-27):

Crianças e adolescentes que crescem em contextos de violência frequentemente apresentam uma série de dificuldades pessoais e interpessoais. É comum a presença de ansiedade, medo, depressão. Podem surgir distúrbios de aprendizagem e de comportamento - falta de atenção, queda de rendimento escolar, irritabilidade e agressividade com os colegas.

Em síntese, o instituto da guarda compartilhada é, como sói acontecer a qualquer um outro instrumento jurídico, neutro. O que não é insípida, incolor e inodora, de outra banda, é a atuação judicial que, a persistir compartimentada como vem sendo, além de apenas pôr fim a processos, transforma-se em uma fonte potencializadora de mais violência não só contra a mulher, mas também contra as crianças e adolescentes envolvidos.

\section{CONSIDERAÇÕES FINAIS}

Em dez anos de sua existência, a aplicação da Lei no 11.340/2006 (Lei Maria da Penha) tem variado, sendo inúmeras as formas encontradas em sede judicial para a solução dos conflitos decorrentes da violência doméstica e familiar contra a mulher, sendo, por concepção, uma norma de caráter protetivo integral, não vinculada necessária ou exclusivamente à incidência de seus efeitos penais. Pelo contrário, é dotada de um caráter multifacetado, que não visa somente à proteção da mulher vítima de violência doméstica e familiar sob a perspectiva criminal.

Embora a Lei Maria da Penha tenha pontualmente alterado alguns dispositivos da legislação penal, assim como impedido a utilização de instrumentos processuais penais advindos da Lei no 9.099/1995, ela é uma norma de natureza transdisciplinar, o que necessariamente significa não ser a alternativa penal a única, ou a mais efetiva, esfera de proteção da mulher em situação de violência. Isto é, a lei indica a necessidade de um esforço integral e não compartimentado do sistema de justiça para a proteção da vítima nesses casos.

O reconhecimento da situação de violência na esfera de família tem de ser um pressuposto para o que será decidido naquela esfera. Somente 
assim restará cumprido o comando legal previsto na Lei Maria da Penha, segundo o qual: "Para os fins desta lei serão considerados os fins sociais a que ela se destina e, especialmente, as condições peculiares das mulheres em situação de violência doméstica e familiar" (art. 4º).

Não raras vezes, a resolução da demanda sob a perspectiva exclusivamente criminal não põe fim à violência. Assim como, também, não poucas vezes, a decisão que determina a guarda compartilhada, sem considerar o contexto de violência doméstica, expõe a mulher (e as próprias crianças e adolescentes) a novos riscos.

Mais do que resolver processos, o que se espera do Judiciário é que resolva conflitos. E resolver conflitos implica assumir o dever constitucional de garantir às mulheres, no âmbito também do Juízo de Família, o direito à proteção.

\section{REFERÊNCIAS}

ALEXY, Robert. Teoría de los derechos fundamentales. Madrid: Centro de Estudíos Políticos y Constitucionales, 2002.

ANGELIM, Fábio Pereira. A importância da intervenção multidisciplinar face à complexidade da violência doméstica. In: LIMA, Fausto Rodrigues. SANTOS, Claudiene. Violência doméstica: vulnerabilidades e desafios na intervenção criminal e multidisciplinar. Rio de Janeiro: Lumen Juris, 2009.

; DINIZ, Gláucia. Violência doméstica - Por que é tão difícil lidar com ela? Revista de Psicologia da UNESP, 2(1), 2003.

BANDEIRA, Lourdes. A contribuição da crítica feminista à ciência. Rev. Estud. Fem., Florianópolis, v. 16, n. 1, abr. 2008. Disponível em: <http://www.scielo.br/ scielo.php?script=sci_arttext\&pid=S0104-026X2008000100020\&lng=en\&nrm=i so>. Acesso em: 4 jul. 2012.

; THURLER, Ana Liési. A vulnerabilidade da mulher à violência doméstica: aspectos históricos e sociológicos. In: LIMA, Fausto Rodrigues. SANTOS, Claudiene. Violência doméstica: vulnerabilidades e desafios na intervenção criminal e multidisciplinar. Rio de Janeiro: Lumen Juris, 2009.

BARATTA, Alessandro . Criminología y sistema penal: compilación in memoriam. Montevideo: BdeF, 2006.

. O paradigma do gênero: da questão criminal à questão humana. In: CAMPOS, Carmen Hein de. Criminologia e feminismo. Porto Alegre: Sulina, 1999a. 
BRASIL. Constituição (1988). Constituição da República Federativa do Brasil. São Paulo: Saraiva, 2016. Código Penal. Decreto-Lei nº 2.848, de 7 de dezembro de 1940. Diário Oficial da União, Rio de Janeiro, 31 dez. 1940.

. Lei no 11.340 , de 7 de agosto de 2006. Diário Oficial da União, Brasília/DF, 8 ago. 2006.

. Lei no 11.698, de 13 de junho de 2008. Diário Oficial da União, Brasília/DF, 16 jun. 2008.

. Lei no 13.058, de 22 de dezembro 2014. Diário Oficial da União, Brasília/DF, 24 dez. 2014.

CUNHA, Dália Maria Moreira da. Impacto da violência conjugal nas práticas educativas parentais: o olhar da mãe. Universidade Fernando Pessoa, 2009. Disponível em <https://bdigital.ufp.pt/dspace/bitstream/10284/1519/1/DM_DaliaCunha. pdf>. Acesso em: 26 out. 2011.

DIAS, Maria Berenice. Manual de direito das famílias. 8. ed. São Paulo: Revista dos Tribunais, 2011.

DINIZ, Glaucia Ribeiro Starling. PONDAAG, Miriam Cássia Mendonça. A face oculta da violência contra a mulher: o silêncio como estratégia de sobrevivência. In: DINIZ, Glaucia Ribeiro Starling et al (Org.). Violência, exclusão social e desenvolvimento humano: estudos em representações sociais. Brasília: Editora Universidade de Brasília, 2006.

FERRAJOLI, Luigi. Direito e razão: teoria do garantismo penal. São Paulo: Revista dos Tribunais, 2006.

. Los fundamentos de los derechos fundamentales. Madrid: Trotta, 2005.

. Por uma teoria dos direitos e dos bens fundamentais. Porto Alegre: Livraria do Advogado, 2011.

MENDES, Soraia da Rosa. Criminologia feminista: novos paradigmas. São Paulo: Saraiva, 2014.

Da carta das mulheres aos dias atuais: vinte e cinco de anos de luta pela garantia dos direitos fundamentais das mulheres. Brasília: IDP, 2013.

OLIVEIRA, André Luiz Pereira. "Se você ficar com nossos filhos, eu te mato!": violência doméstica e familiar contra a mulher e as disputas de guarda de filhos(as) em trâmite nas Varas de Família de Ceilândia/DF. Dissertação de Mestrado pela Universidade de Brasília, 2015.

OPTIZ, Claudia. O quotidiano da mulher no final da Idade Média (1250-1500). In: PERROT, Michelle; DUBY, Georges (Org.). História das mulheres no Ocidente. Idade Média. Porto: Afrontamento, v. 2, 1990. 
PINTO, Céli R. Jardim. Uma história do feminismo no Brasil. São Paulo: Editora Perseu Abramo, 2003.

PITANGUY, Jaqueline. As mulheres e a Constituição de 1988. Disponível em: <http://www.cepia.org.br/images/nov089.pdf>. Acesso em: 10 out. 2012.

SAFFIOTI, Heleieth I. B.; ALMEIDA, Suely Souza de. Violência de gênero: poder e impotência. Rio de Janeiro: Revinter, 1995.

SCOTT, Joan W. Gênero e história. México: FCE, Universitad Autónoma de la Ciudad de México, 2008.

TABAK, Fanny. Mulheres públicas: participação política e poder. Rio de Janeiro: Letra Capital, 2002.

VECCHIO, Silvana. A boa esposa. In: PERROT, Michelle; DUBY, Georges (Org.). História das mulheres no Ocidente. Idade Média. Porto: Afrontamento, v. 2, 1990. 


\title{
O Judiciário na Trincheira do Direito Fundamental à Saúde: uma Proposta de Reanálise do Problema da Judicialização das Políticas Públicas à Luz das Teorias do Substancialismo e do Procedimentalismo
}

\author{
MÔNICA BONETTI COUTO \\ Professora permanente do Programa de Mestrado em Direito da Universidade Nove de Julho. \\ SIMONE PEREIRA DE OLIVEIRA \\ Mestranda em Direito pela Universidade Nove de Julho, Especialista em Medidas de Urgência \\ no Processo Civil, Assistente Jurídico.
}

RESUMO: 0 presente artigo tem por finalidade realizar uma breve incursão no problema da recorrente judicialização das políticas públicas instituídas pela Constituição e não efetivadas pelo Poder Público, com especial enfoque na questão correlata à efetivação do direito social fundamental à saúde. Neste empreendimento foram consideradas duas teorias distintas que se propõem a fornecer subsídios interpretativos para solução da divergência doutrinária relativa à delimitação do papel do Poder Judiciário e da justiça constitucional quanto à efetivação dos direitos fundamentais, o procedimentalismo e o substancialismo. Foram analisadas algumas das mais paradigmáticas decisões do Supremo Tribunal Federal quanto à efetivação do direito à saúde, questionando-se, em face do procedimentalismo e do substancialismo, qual seria a melhor proposta para direcionamento da atuação da prestação jurisdicional no Brasil para o cumprimento dos compromissos constitucionais de erradicação da pobreza e da marginalização e garantia de acesso universal à população ao direito à saúde. A pesquisa adota os métodos hipotético-dedutivo de abordagem e indutivo. Serve-se, ademais, do método dialético, com o objetivo de buscar possíveis sínteses para as divergências levantadas. Quanto ao procedimento, utilizará os métodos histórico e comparativo, fazendo uso da interpretação sistemática, servindo-se, quanto ao tipo de pesquisa, da documental (bibliográfica).

PALAVRAS-CHAVE: Judiciário; políticas públicas; substancialismo; procedimentalismo; direito fundamental à saúde.

ABSTRACT: This article aims to conduct a brief analysis concerning the judicial intervention in the implementation of public policies instituted by the Constitution and not effected by the Government, with special focus on realization of the fundamental social right to health. This venture were considered two distinct theories that purport to provide interpretative subsidies for solution of doctrinal 